\title{
Grumbiteuergeies
}

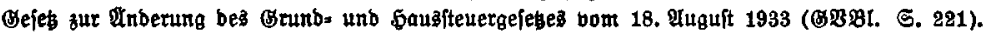

Daş Baberifhe Bejamtmintifterium hat ars Sandeşregierung auf

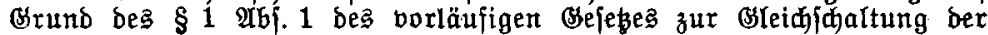

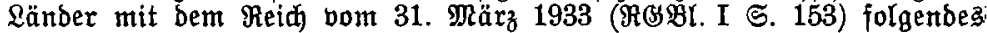
Gefes bejhloifen:

\section{Art. 1}

Daş Urundfteuergefę wirb toie folgt geändert:

1. \$ 118 exhält folgende ₹afflung:

"Den Beitpuntt ber Fälligteit und ber Entriøtung ber Srund

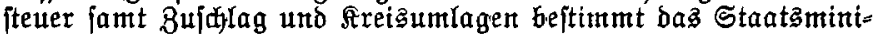
fterium ber Finanzen im cinbernehmen mit ben beteiligten Slaatz: minifterien."

2. $\S 123$ abj. V Sał 1 hat zu Iauten:

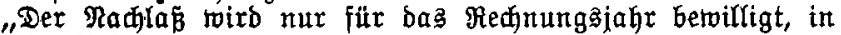
bem bie Bejuäbigung eingetreten ift."

Art. 2

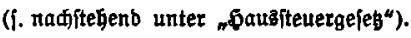

Urt. 3

Diejes Sejes tritt mit ßirfung vom 1. Ulpril 1933 an, bezüglich bes Art. 1 Biff. 1 und bes $\mathfrak{A}$ rt. 2 Biff. 2 mit jeiner Bertünoung in Rraft.

\section{Gauspiteuergeieg}

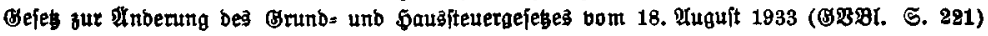

Das Bayerijue Gejamtminijterium hat als Landes̉regierung auf

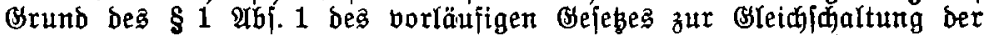

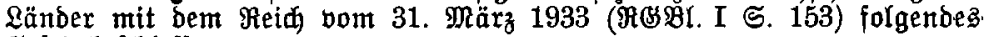
Sejes bejalofien:

$$
\text { Urt. } 1
$$

(f. voritebent unter "(Grubiteutergeies").

Art. 2

Das Sausfteuergefeb wirb wie forgt geändert:

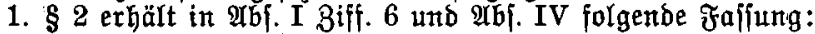

I. Sgausteuerfiret find ........

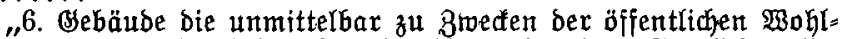

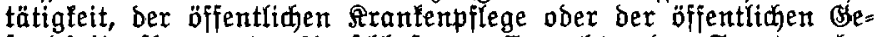
fundheit bienen. Die Berfolgung von Sportzwefen fteht ber 5 zausjteuer= befreiung nidgt entgegen, twenn bie bebäube im Eigentum von

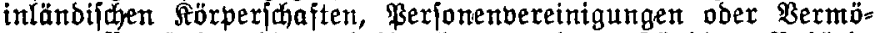
genżmaffen ftehen, bie nach anerfennung ber zultändigen Bełörde

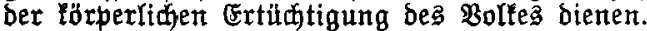

IV. Anderungen, bie fid hinjthttich ber Borausfełungen für bie Steuer= beranlagung ergeben, finb von bem auf bie ânderung nädhitfolgen= ben Monat zu berürtjiłtigen." 
2. \$ 36 hat zu lauten:

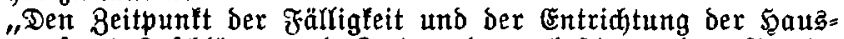

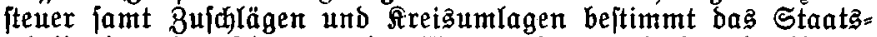
minijterium ber Finangen im Einbernehmen mit ben beteiligten Staatsminifterien."

3. $\mathfrak{A n}$ bie Stelle ber $\$ \S 39$ mit 42 treten folgende Beftimmungen:

$$
\text { ,\$ } \$ 9
$$

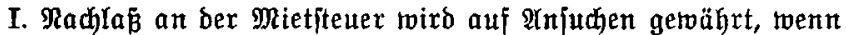
zor Bermietung beftimmte Bohnungen oder Gejchäjtäräume ins folge bon Leeritehen, Mietaugfall ober Billigerbermietung leinen ober einen geringeren Extrag abgeworfen haben und ber Miet= entgang unter 3ugrundelegung Der fteuerbarent Frriebensmiete ber Räume mindeitens ben zıölftent Teil ber iteuerbaren Friedensmiete Des Brebäubes beziffert. Şat ber Mrliditige ben Mietentgang ver=

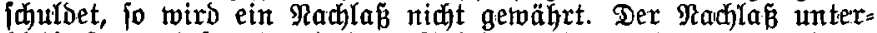
bleibt ferner infoweit, als ber Pflichtige in bem Mietertrag anderer

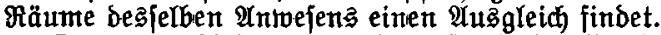

II. Der Madhla baren Friedensmiete fefrgefest. Bon bem Betrage ber Minberung find etraaige (Entj山äbigungen abzuziehen.

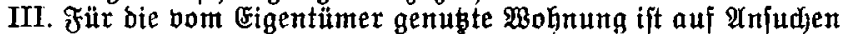
Rad)la

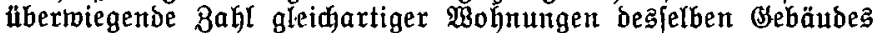

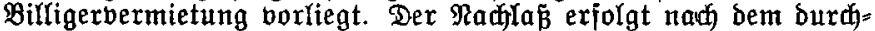

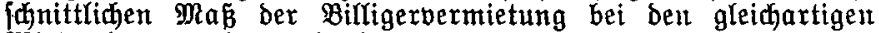
Mietrohnungen bes Bebäubes.

\section{$\$ 40$}

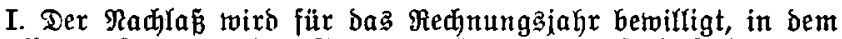

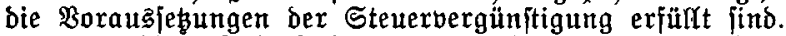

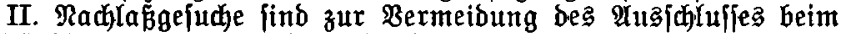

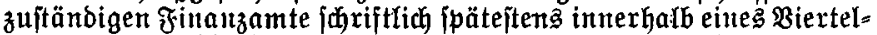

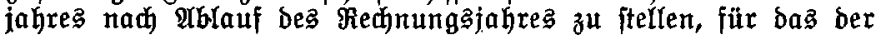

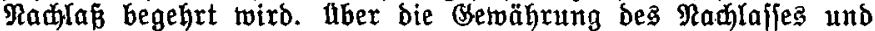

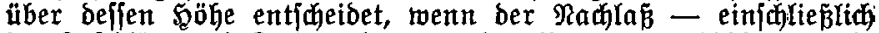

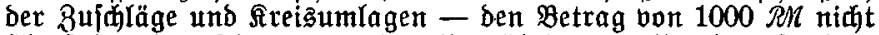
überiteigt, das Fintanzamt, in allen übrigen Fälfen bas Lanbes= finanzamt (Rantesmittelftelle). Begen bie Berfügunt bes Finanz= amts ift Beidgreerbe an bas Landegfinanzant, gegen die Entidjlie= buttg bes Lanbeâfinanzamts ift Beidjwerbe an bas Staatsmint=

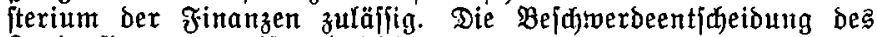
Landesfinanzamts ift endgültig.

\section{\& 41}

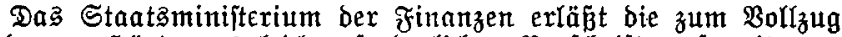
uno zum Б̧ärterausgletch exforberlid)er Borjdrifter, joweit ver= anlaß̧t im Benehmen mit ben beteiligten Staatsminifterien."

Irt. 3

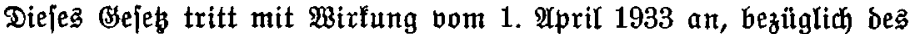
Art. 1 Biff. 1 unb des 2 rt. 2 Biff. 2 mit feiner Berfündung in ßraft. 